\title{
Ensino de literatura e a formação do leitor literário na escola: dos primeiros passos à vida
}

\author{
The teaching of Literature and the literary reader's formation: \\ from the first steps to the whole life
}

\author{
Gilmei Frasncisco Fleck ${ }^{*}$ \\ Universidade Estadual do Oeste do Paraná- Unioeste \\ Cascavel, Paraná, Brasil
}

\begin{abstract}
Resumen: Procuramos refletir neste texto sobre a importância da formação do leitor, especialmente do leitor literário, no espaço institucional escolar. Essa formação no nosso contexto de ex-colônia significa passos necessários ainda à descolonização. Sabemos que a presença da Literatura no espaço do Ensino Fundamental não está garantida pela instituição de uma disciplina específica, ficando, assim, sob a responsabilidade dos professores a decisão de incluí-la, ou não, no reportório de leitura dos alunos. O texto literário, por ser de natureza aberta, é um dos modos mais eficazes de confrontar o aluno com as múltiplas possibilidades de manipulação da linguagem. A escola historicamente foi usada como canal para manter muitos dos princípios da colonização ativos e em ação na nossa sociedade, contribuindo para a manutenção da estratificação social e a elitização do aprendizado das habilidades de leitura e escrita. Frente a essa realidade procuramos expor a importância da mediação do professor no processo de leitura do texto literário como uma via privilegiada para a descolonização. Desse modo, a alfabetização precisa ir além da decodificação proficiente dos signos linguísticos e promover o entendimento de que a simbolização feita pela linguagem é um processo manipulável. Nesse sentido, o texto literário é o meio mais produtivo e um excelente caminho para mostrar isso aos estudantes, pela sua natureza artística e lúdica.
\end{abstract}

Palabras clave: Ensino de Literatura. Texto Literário. Mediação leitora. Descolonização

\begin{abstract}
Along this text we try to think about the reader's formation, especially the reader of literary texts, inside the formal school institution. In our reality of ex colony this formation means still the necessary steps towards decolonization. We know that the presence of Literature along the years of Elementary School is not guaranteed by the presence of a specific discipline, so that the use, or not, of literary texts among the reading subjects in the classroom is a decision that teachers are responsible to take. The literary texts, by their characteristic of being an open text, are one of the most efficient ways to confront the students with different possibilities of language manipulation. Historically the school has been used as a channel to keep many of the principles of colonization active and in affective action, contributing to the social stratification and the eletization of the processes of reading and writing in our society. Facing this reality, we discuss about the importance of the teacher's mediation along the process of reading literary texts as a privileged way of decolonization. Therefore alphabetization needs to go further than just decodifying proficiently the linguistic signs and so promote the understanding that the symbolization made through language is a manipulating system. In this way, the literary texts are the most productive and an excellent way to show this to the students by their artistic and ludic nature.
\end{abstract}

Keywords: Literature teaching. Literary Texts. Reading mediation. Decolonization

* Pós-doutor em Literatura Comparada e Tradução pela Uvigo-Vigo/Espanha, Doutor em Letras pela UNESP-Assis-SP/Brasil. Professor associado da Unioeste/Cascavel-PR/Brasil. Líder do grupo de pesquisa "Ressignificações do passado na América: processos de leitura, escrita e tradução de gêneros híbridos de história e ficção - vias para a descolonização", cadastrado na Capes. E-mail: chicofleck@yahoo.com.br 


\section{INTRODUÇÃO}

Embora a história da formação leitora de um sujeito tenha início, e esse pode ser sua própria presença na vida, ela não tem fim, pois traços de sua formação podem se estender além de sua própria existência, como modelo e como inspiração. Nessa trajetória, o espaço histórico, social e cultural da escola desempenha um papel crucial, sem desmerecer aquele da família e da sociedade como um todo. É na instituição escolar que o leitor se revela em suas múltiplas aptidões e é ali, também, onde elas são, com maior frequência, postas em xeque.

A escola, como espaço de formação instituído pelo poder, é o ambiente no qual a leitura é realizada de forma pública, exposta e, muitas vezes, avaliativa. Se nele o sujeito não se sair bem é muito provável que levará para o trajeto dessa caminhada as mazelas destas experiências malfadadas. É este também o lugar privilegiado onde a Literatura pode e dever ser ensinada como prática social capaz de gerar no sujeito leitor inquietações que o levarão a buscar, ao longo desta caminhada formativa, pelas tantas outras perspectivas possíveis sobre o poder de representação das palavras e suas vias de manipulação. Isso ocorre porque a natureza do texto literário é sempre aberta, multisemântica, diferenciando de outros textos nesta sua essência de arte. Tal arte é constituída a partir do poder representativo, expressivo, metafórico dos signos linguísticos submetidos à capacidade, à habilidade e à sutileza do literato em manipular seus sentidos e usos a fim de gerar imagens múltiplas de uma mesma temática, produzidas com base, também, nas experiências de vida do próprio leitor. Este é quem lhe atribui valor e sentido, num processo dialógico que relaciona seu universo cotidiano de existência com a representatividade daquela visão de mundo do autor plasmada, de várias formas, na obra.

Nesse sentido é necessário que se atente ao fato de que as condições de existência humana são construídas por meio da mediação dos signos e do desenvolvimento da consciência, já que "a consciência é a expressão ideal do psiquismo, desenvolvendo-se graças à complexificação evolutiva do sistema nervoso central pela decisiva influência do trabalho e da linguagem." (MARTINS, 2013, p. 28). O significado da palavra signo vem (do latim signum) é o elemento que designa ou indica "outro". Objeto que representa outro, elemento sensível de expressão cultural organizativo do comportamento humano que encerra uma materialidade (sinal) e ocupa o lugar de algo por ele representado.

Ao operar ao nível da consciência dos indivíduos, todo signo demanda decodificação. Ao introduzir o conceito de signo, Vigotski diz que o desenvolvimento do psiquismo, pelo viés tradicional, não compreende as condições culturais do indivíduo, mas é somente por meio da internalização dos signos construídos historicamente e mediados pelo outro que se institui o homem como ser humano. Diante do exposto, é possível dizer que o comportamento do homem é mediado por signos. No entanto, o sujeito precisa internalizá-los, uma vez que a natureza do processo externo dos signos necessita de elementos internos para que, dessa maneira, eles possam se estabelecer como fenômeno da subjetividade. Assim, o processo de mediação, segundo Vigotski, não incide simplesmente sobre as funções como ponte, como meio 
de ligação, mas sim, a "[...] mediação é a interposição que provoca transformações, encerra intencionalidade socialmente construída e promove desenvolvimento." (MARTINS, 2013, p. 46). Desse modo, a seguir, discutimos sobre o processo de leitura e sua instauração no espaço escolar bem como a sua importância na caminhada de formação do estudante.

\section{A ESCOLA E A LEITURA: UMA RELAÇÃO PARA TODA A VIDA}

A relação entre a escola, a leitura e a escrita é uma das mais esperadas entre os grandes desafios que a primeira infância impõe ao ser humano. Tão vital quanto outras na adaptação do sujeito ao mundo, ela determina como será a relação subjetiva do indivíduo frente às necessidades de comunicação e expressão mais frequentes e, em nossa sociedade, em especial, mais valorizadas. Ela determina o sucesso nas interrelações sociais, abrindo portas e apresentando oportunidades, inclusive de romper barreiras impostas pela estratificação social historicamente construída em nossa sociedade. A escola é o espaço que tem como função primordial possibilitar a todos os estudantes o domínio da leitura e da variedade padrão da língua escrita.

$\mathrm{Na}$ realidade vivenciada em sala de aula, porém, a leitura e a escrita, têm sido sempre um grande desafio aos professores que trabalham cientes dessa função essencial do Ensino Fundamental, pois, para o indivíduo aprender a falar e a ouvir não precisa, necessariamente, da escola, mas, para ler e escrever bem, ela é imprescindível. Tal processo não alcança sucesso sem a mediação do professor que, antes de tudo, deve ser leitor experiente e escritor proficiente. Tais condições parecem óbvias para um profissional da educação, contudo, na realidade histórica da formação docente no nosso país elas sempre foram negligenciadas. Saviane (2009, p. 144), em seus estudos sobre a Educação no Brasil, registra, entre outras informações relevantes, que:

Durante todo o período colonial, desde os colégios jesuítas, passando pelas aulas régias implantadas pelas reformas pombalinas até os cursos superiores criados a partir da vinda de D. João VI, em 1808, não se manifesta preocupação explícita com a questão da formação de professores.

Nesse período, segundo Ramalho, Nuñez e Gauthier (2004), os professores trabalhavamm como artesões, já que

[...] essa tradição vai perdurar até o século XX, sem grandes modificações. [...] Esse comportamento constitui o início da consciência de que para ensinar não basta dominar o conteúdo, mas também é necessário o conhecimento de um método e de estratégias para desenvolvê-lo. O mestre não pode ser improvisado. [...] Entretanto, não há um método científico de ensino, mas apenas troca de receitas. Isso evidencia que não se pode falar ainda num profissional do ensino. A formalização da maneira de ensinar deu origem a um modelo de "profissional" particular e à chamada pedagogia tradicional que traduzia a maneira artesanal e uniforme de ensinar. (RAMALHO; NUÑEZ; GAUTHIER, 2004, p. 25).

Nesse sistema educacional elitizado, a aprendizagem da leitura e da escrita - 
conhecimentos fundamentais para o desempenho da cidadania e para a ascensão social não encontrou na escola o local adequado para realizar seu papel democratizante das oportunidades de crescimento. A experiência da vida escolar é decisiva para a experiência de leitura e, consequentemente, para a de mundo. Sabemos que esta experiência em nossos dias segue em crise, debilitada e desestruturada, pois não produz os frutos que dela se espera. Com o passar dos anos se instituíram na própria escola muitos mecanismos que não permitiram o surgimento de uma grande massa de cidadãos capazes de efetuar uma leitura crítica, conscientizadora e transformadora e a escola foi um dos canais usados para atingir esses objetivos. Assim, a leitura, em sua plenitude de ação e exercido de poder, continua sendo privilégio de uma pequena elite brasileira ainda nas primeiras décadas do século XXI.

Transformar a nossa sociedade passa, necessariamente, por mudar a sua mentalidade colonizada - que parte da ideia de superioridade de uns sobre outros, da subserviência, da subjugação e da exploração - e a educação é a única via para alcançar tamanha proeza. A leitura - que segue a trajetória da tradição às rupturas necessária à inovação - é, sem dúvidas, a mais indicada das rotas nessa jornada de descolonização.

Para Montes (2001, p. 32), “[...] a história do leitor, que começa precocemente quando ainda não é alfabetizado, é uma história sem fim. Não se inicia na alfabetização nem termina na universidade; confunde-se com sua própria vida, num caminho de construção e descobrimento". É, contudo, da escola que se cobram resultados, quando já está bem claro que o processo de formação leitora - tratando-se de um sujeito proficiente no processo - é um projeto histórico-social ancorado nas relações vitais que o sujeito estabelece com a família, a escola e todas as demais instituições que compõem o todo social com o qual ele interage. Vivendo em uma sociedade não leitora, é difícil querer ser leitor, chega a ser estranho, atípico, meio raro... E, no momento em que a escola se transforma neste espelho histórico da formação de nossa sociedade, a formação do leitor está em perigo, mais ainda a do leitor literário.

Há grande necessidade de se mediar os diferentes níveis de leitura que, segundo Martins (2012), podem ser considerados o sensorial, o emotivo e o racional: Esses níveis referem-se ao modo como nos aproximamos do objeto lido e, após a sua efetiva aprendizagem, eles podem ocorrer de forma simultânea, mesmo que seja "um ou outro privilegiado, segundo a experiência, expectativas, necessidades e interesses do leitor e das condições do contexto geral em que se insere." (MARTINS, 2013, p. 37). O aperfeiçoamento de cada um deles conduz à caminhada rumo ao aprendizado do próximo e, finalmente, à tão comentada leitura crítica do mundo.

A entrada da criança no sistema educacional formal leva, necessariamente, à alfabetização. Como devemos conceber esse processo nos dias atuais? Magda Soares (1998), já nos dava respostas a essa questão no final do século passado, ao mencionar que

Alfabetização é dar acesso ao mundo da leitura. Alfabetizar é proporcionar condições para que o indivíduo - criança ou adulto - tenha acesso ao mundo da escrita, tornando-se capaz não só de ler e escrever, enquanto habilidades de decodificação e codificação do sistema de escrita, mas, e sobre tudo, de fazer uso real e adequado da escrita com todas as funções que 
ela tem em nossa sociedade e também como instrumento na luta pela conquista da cidadania plena. (SOARES, 1998, p. 33).

Nesse processo não temos como isolar escola, leitura, escrita e sociedade. Assim, para poder ler é preciso saber ler. Para gostar de ler, também é preciso saber ler, então, a porta de entrada para a leitura, é, também, responsabilidade da escola e do professor. Eles são elementos centrais no desenvolvimento do trabalho pedagógico com as práticas e estratégias de leitura que, muitas vezes, a família não está preparada para oferecer. Portanto, a primeira tarefa da escola consiste em assegurar um adequado processo de iniciação à leitura como prática sociocultural, vinculada ao prazer e à apreciação dos significados atribuídos ao texto. Aprender a ler e a escrever torna-se, conforme Saviani (2005, p. 15), "a primeira exigência" do acesso à cultura letrada.

Nesse sentido Cagliari (1998, p. 312) afirma que

[...] ler é decifrar e buscar informações. Já se sabe que o segredo da alfabetização é a leitura. Alfabetizar é, na sua essência, ensinar alguém a ler, ou seja, a decifrar a escrita. Escrever é em decorrência desse conhecimento e não o inverso. Na prática escolar, parte-se sempre do pressuposto de que o aluno já sabe decifrar a escrita, por isso o termo "leitura" adquire outro sentido. Trata-se, então, da leitura para conhecer um texto escrito. $\mathrm{Na}$ alfabetização, a leitura como decifração é o objeto maior a ser atingido.

Neste sentido, Martins (2012, p. 34), declara: "Assim, criar condições de leitura não implica apenas alfabetizar ou propiciar acesso aos livros. Trata-se, antes, de dialogar com o seu leitor sobre sua leitura, isto é, sobre o sentido que ele dá, repito, a algo escrito [...]: um quadro, uma paisagem, sons, a imagens, [...]". O sistema escolar brasileiro colocou, ao longo da trajetória do Ensino Fundamental, muito mais ênfase no domínio do sistema de escrita, insistindo na reprodução gráfica das palavras, enquanto o desenvolvimento de capacidades que conduzem à formação leitora proficiente necessárias à compreensão da passagem da concretude à representação - acaba sendo minimizados pela "falta de tempo" para dar conta dos conteúdos programáticos. Essa inversão na lógica natural de aprendizado das macro destrezas (ouvir, falar - adquiridas já antes da alfabetização - ler e escrever - essenciais à alfabetização \letramento) acarreta prejuízos consideráveis, que nem sempre são fácil de serem remediados na trajetória estudantil.

Conforme afirma Cagliari (2005, p. 160), na escola, a leitura é “[...], o melhor, a grande herança da educação. É o prolongamento da escola da vida, já que a maioria das pessoas, no seu dia a dia, lê muito mais do escreve. Portanto, deveria se dar prioridade absoluta à leitura no ensino da língua portuguesa, desde a alfabetização." A escola necessita buscar meios para solidificar a prática de leituras no seu interior, propiciar o desenvolvimento do sujeito e conduzir o aluno à apropriação da riqueza contida em uma obra literária, contribuindo para a formação do gosto do leitor pela arte literária, pois "a leitura seria a ponte para o processo educacional eficiente, proporcionando a formação integral do indivíduo." (MARTINS, 1994, p. 25).

A leitura é algo que precisa ser aprendido, pois, segundo Antunes (2009, p. 201), "não se nasce com o gosto pela leitura, [...]. O ato de ler não é, pois, uma habilidade 
inata. [...] o gosto por ler literatura é aprendido por um estado de sedução, de fascínio, de encantamento. Um estado que precisa ser estimulado, exercitado e vivido." Então, a leitura é um ato social essencial para a formação humana, aprende-se a ler para ler criticamente o mundo, para buscar os sentidos no texto que são determinados pela bagagem sociocultural que o leitor traz consigo.

Nesse sentido, cabe ressaltar que "a literatura nos prepara para ler melhor todos os discursos sociais." (COLOMER, 2007, p. 36). Portanto, a literatura nos propicia caminhar por distintas veredas, presenteia-nos com aprendizagens significativas, com experiências que contribuem com a compreensão do mundo que nos rodeia por meio da fantasia e do imaginário. Diante dessa experiência, o leitor, fundamentado na sua leitura de mundo, pode dialogar com o texto, levantar outras questões, e desenvolver-se culturalmente. Nesse sentido, Antonio Candido (1989, p. 113) menciona que "os valores que a sociedade preconiza, ou os que consideram prejudiciais, estão presentes nas diversas manifestações da ficção, da poesia e da ação dramática. A literatura confirma e nega, propõe e denuncia, apóia e combate, fornecendo a possibilidade de vivermos dialeticamente os problemas."

Uma vez instaurada a fase inicial da alfabetização e o aluno comece a dar passos seguros no processo fundamental de decodificação dos signos linguísticos, há que considerar-se uma nova fase. É nessa etapa que

[...] a leitura escolar deve contemplar o aspecto formativo do educando, estimulando-lhe a sensibilidade estética, a emoção, o sentimento [...] o texto literário tem muito a contribuir para o aprimoramento pessoal, para o autoconhecimento, sem falar do constante desvelamento do mundo e da grande possibilidade que a leitura de determinada obra oferece para o descortínio de novos horizontes para o homem, no sentido da formação e do refinamento da personalidade. (SILVEIRA, 2005, p. 16).

A importância da leitura do texto literária fica claramente expressa nas palavras de Aguiar e Bordini (1988, p. 15) quando afirmam:

A riqueza polissêmica da literatura é um campo de plena liberdade para o leitor, o que não ocorre em outros textos. Daí provém o próprio prazer da leitura, uma vez que ela mobiliza mais intensa e inteiramente a consciência do leitor; sem obrigá-lo a manter-se nas amarras do cotidiano. Paradoxalmente, por apresentar um mundo esquemático e pouco determinado, a obra literária acaba por fornecer ao leitor um universo muito mais carregado de informações, porque o leva a participar ativamente da construção dessas, com isso forçando-o a reexaminar a sua própria visão da realidade concreta.

Já nessa fase, em diálogo com o texto literário, o aluno pode sentir-se coautor sem dominar a completude do processo de escrita -, pois, sendo o texto literário de natureza "aberta", a participação do leitor torna-se tão significativa na atribuição de sentidos e significados para essa categoria de textos artísticos que ele só se completa nesse processo recepcional, o que não passa com outros gêneros textuais de estruturas "fechadas". A oralidade, aqui, serve de meio de expressão e completude para os textos lidos. Contudo, o que vemos no processo de escolarização da leitura é um imediatismo em direção à produção escrita. Quando o pequeno aprendiz mal consegue decifrar ou 
decodificar palavras é conduzido já a reproduzi-las na sua forma escrita.

Essa conexão da criança com o texto literário, que liberta as "palavras" de sua prisão denotativa, que extrapola os limites do real, prepara-a no começo do processo de alfabetização \letramento para aceitar a simbolização da escrita de forma menos traumática e dela também se valer como meio privilegiado de se comunicar, seja dando ênfase ao sentido denotativo da linguagem - para transmitir algo preciso e exato - ou valendo-se dela para dar asas à imaginação, à fantasia - ao se arriscar a poetizar pelo uso conotativo da linguagem. A mediação do professor pode dar-se pela contação de histórias ou leituras dramatizadas, quando a turma ainda não lê com desenvoltura, ou pela instigação ao desvelamento das metáforas ou das construções simbólicas.

Nesse sentido, a utilização do texto literário na alfabetização, por meio das práticas de ler e ouvir histórias pode, sim, contribuir no processo de transição da fala para a escrita, ou seja, na aquisição e manejo do código escrito (ampliação vocabular, incorporação de estruturas linguísticas, etc). Como pontua em outra ocasião, "da leitura (literária) não se extraem apenas vocábulos, mas formas e estruturas, gêneros e estilos que se projetarão, futuramente, no uso da linguagem e na redação individual e própria do leitor." (FLECK, 2017, p. 30). Cabe aqui ressaltar que essa prática com o texto literário deve ser de natureza quantitativa e qualitativa: é necessário que o professor propicie ao aluno o acesso a vários tipos de textos e obras, sem perder de vista a qualidade (estética e linguística) de cada uma delas. Assim, aprender a ler e a escrever, apesar de ser uma tarefa complexa, pode se tornar mais fácil se, desde o início, a criança encontrar um ambiente rico e motivador, que estimule novas descobertas e que oportunize, gradativamente, o contato com as complexidades da língua. É o que nos aponta Cagliari (1992), quando menciona:

[...] uma criança pode começar ouvindo histórias, aprendendo a decifrar os sons das letras (no seu dialeto e no da escola) em diversos contextos (palavras diferentes), e se pôr a ler pequenos textos de cujo conteúdo já tem conhecimento (já ouviu) ou que sabe de cor, como canções, provérbios, adivinhações etc. Se esse tipo de atividade for intensificado, a criança passa a ter um outro tipo de contato com a escrita, que não é simplesmente um jogo de montar e desmontar sílabas e palavras. (CAGLIARI, 1992, p. 168).

Nesse contexto, a literatura infantil e infantojuvenil - e seu ensino consciente e programado - vem a solidificar o espaço da leitura na escola enquanto formação de leitores literários, tendo em vista que ela pode proporcionar a possibilidade de a criança adentrar num mundo diferente: num mundo de sonhos e ações das personagens das histórias, que desmistificam preconceitos e permitem-lhe relacionar fatos com sua própria vida, numa forma de tornar o mundo mais compreensível e mais humano. Desse modo, se investirmos um pouco mais de tempo na formação do leitor literário na escola, antes de confrontarmos as crianças com o processo de produção escrita, podemos, seguramente, contar, também, com escritores mais proficientes ao longo da caminhada. Não cercear o mundo imaginativo e fabulativo das crianças quando elas entram na escola com limitações impostas pela linguagem denotativa - a qual também devem aprender a conhecer e utilizar ao longo do processo - é apostar no sucesso da 
caminhada à formação leitora.

Uma das formas mais eficientes e prazerosas para a criança estabelecer o trânsito da concretude à simbolização é pela aproximação com o texto literário. Texto este criado a partir da premissa da arte, do uso da linguagem no seu sentido figurado, metafórico, simbólico, portanto, distanciado do sentido denotativo, limitado e condicionante de conceber a língua escrita, ou a própria linguagem em si.

Textos instigadores da imaginação, da fantasia, da possibilidade de extrapolar a realidade concreta são comuns na poesia e na narrativa literária, desde clássicos mundiais - como Alice no país das Maravilhas, de Lewis Carol - até obras consagradas da literatura infantojuvenil brasileira - como as produções de Monteiro Lobato, Reinações de Nariz̧inho, etc. - e são meios disponíveis de levar as crianças a, ludicamente, lidar com o processo de "representação" e "simbolização" tão necessários para que haja uma boa relação da criança com a escrita. Isso, contudo, não ocorre de forma automática. É a vital função mediadora do professor que possibilitará esse trânsito.

Segundo Antunes, "não se nasce com o gosto pela leitura, [...]. O ato de ler não é, pois, uma habilidade inata. [...] o gosto por ler literatura é aprendido por um estado de sedução, de fascínio, de encantamento. Um estado que precisa ser estimulado, exercitado e vivido.” (ANTUNES, 2009, p. 201). Nas palavras de Gonçalves (2009, p. 17), vemos que "a leitura literária constitui, através do prazer e da descoberta que pode proporcionar, um caminho de aprendizagem da língua que contribui para a formação integral do ser humano." Para o mencionado autor, "o Ensino da Literatura legitima-se na convicção de que a leitura de textos literários constitui um componente relevante na formação cultural do leitor e no seu reconhecimento do mundo, dos outros e de si mesmo." (GONÇALVES, 2009, p. 17). É, pois, esse processo de construção de visão de mundo e de si mesmo que o texto literário desperta no sujeito. Por isso a escola deve estar preparada para mediar esse processo, já que é ele que conduz à realização efetiva do sucesso escolar.

\section{O ÁRDUO CAMINHO DA LEITURA NA ESCOLA: DA TRADIÇÃO CANÔNICA ÀS RUPTURAS DA PÓS-MODERNIDADE}

A problemática que hoje enfrentamos em um grande número de escolas e turmas escolares no nosso país se centra no uso que a escola, muitas vezes, faz da ideia do que é ler e, em várias ocasiões, parece que as práticas escolares de leitura ficaram estagnadas nas primeiras concepções de leitura como decifração do código escrito porque elas são, em grande medida, reflexos do nosso próprio processo de aprendizado. Nesse sentido, embora seja muito complicado, complexo e desafiador, precisamos admitir que, atualmente, os alunos:

-Não leem mais como nós lemos quando alunos fomos;

-Não se valem dos mesmos mecanismos ou estratégias que nós empregamos quando eram ainda jovens estudantes;

-Não se interessam pelos mesmos assuntos pelos quais nós tínhamos predileção e nem pelas mesma obras; 
- Muitas vezes não usam, nem valorizam, os suportes que estavam disponíveis para nós enquanto aprendizes iniciais de leitura.

Com relação à prática de leitura normalmente efetivada ao longo dos anos na escola, Martins (2005) comenta que

[...] na escola, diante da imposição das leituras idealizadas pelos professores e pelos livros didáticos, constrói-se o mito de que a leitura literária é difícil, complexa e inacessível para os alunos, subestimando-se a capacidade interpretativa dos educandos. Soma-se a isso o fato de a escola enfatizar a leitura dos textos clássicos, com o objetivo de, à primeira vista, "facilitar" o contato do aluno com obras canônicas para depois desenvolver a leitura de textos mais contemporâneos e experimentais. (MARTINS, 2005, p. 17).

Impor a leitura do cânone na escola, seja em que etapa for, sem que se tenha trilhado o caminho do hábito, do gosto e do prazer pela leitura, e sem se levar em conta a prática efetiva dos jovens, é uma atividade insana que não conduz aos resultados esperados. Nesse sentido, deveríamos repensar a questão de tentar trazer para a sala de aula, como estratégia de aproximação, os artefatos culturais de leitura que têm apelo entre os nossos estudantes, como forma de valorizar o seu universo cotidiano no espaço escolar. Tais artefatos, uma vez valorizados e inseridos no contexto de aprendizagem, podem servir como forma para seduzi-los e instigá-los a ler, sem que o preconceito limite as possibilidades de exploração de sentidos e de ampliação do horizonte de expectativas dos jovens sob pena de afastá-los, ainda mais, do universo das narrativas ficcionais avalizadas pela instituição. Tal prática não desmerece a leitura literária, nem a exclui, mas pode ter a vantagem de atualizar o sentido de ler na escola.

Nesse sistema social e histórico evolutivo, a aprendizagem da leitura e da escrita conhecimentos fundamentais para o desempenho da cidadania e para a ascensão social não encontrou ainda na escola o local adequado para realizar seu papel democratizante das oportunidades de crescimento. A experiência da vida escolar é decisiva para a experiência de leitura e consequentemente para a de mundo. Com o passar dos anos se instituíram na própria escola muitos mecanismos que não permitiram o surgimento de uma grande massa de cidadãos capazes de efetuar uma leitura crítica, conscientizadora e transformadora e a escola foi um dos canais usados para atingir esses objetivos.

$\mathrm{Na}$ instituição escolar, a árdua tarefa do ensino da leitura - a mais essencial na educação básica - está relegada aos professores alfabetizadores e aos de língua (materna ou estrangeira) em praticamente todas as instituições. Assim, a eles cabe a consciência de que as habilidades de ler e escrever sempre estiveram irmanadas com as camadas más altas da sociedade. Desse modo, sempre foram utilizadas como meio de controle e seleção para a ascensão social. $O$ atual mundo da leitura da literatura infantil e infantojuvenil na escola é, ainda, bastante seletivo e, na maioria das vezes, revela o estado conservador da prática de leitura literária. Assim, seguem presentes as obras clássicas que deram, de certo forma, configuração à Literatura Infantil. Vigoram, na atualidade, textos do primeiro ciclo (1890-1920) que marcou a história da Literatura Infantil no nosso país que engloba as produções anteriores à Monteiro Lobato: 
traduções, adaptações, ou mesmo textos genuinamente brasileiros, mas que apresentava como característica central um enfoque moralizante, advindo do universo adulto:

- Fábulas de Esopo, Fedro e La Fontaine;

- Contos clássicos dos irmãos Grimm; de Hans Christian Andersen e de Charles Perrault, entre outros.

O segundo ciclo (1921-1944) dessa Literatura é marcado pelas produções de Monteiro Lobato, que apresenta uma nova forma de escrita para as crianças, rompendo com os modelos anteriores e inovando na linguagem. Tal produção, em algumas escolas, segue tendo sua leitura cultivada, juntamente com as produções canônicas da poesia infantil e infantojuvenil de Cecilia Meireles (1901- 1963). Segue-se à terceira fase, na qual o modelo predominante é Lobato. Num período de transição entre o terceiro e o quarto ciclo de nossa Literatura Infantojuvenil surgem nomes destacados como os dos autores bem conhecidos: José Pualo Paes (1926-1998); Ruth Rocha (1931); Lygia Bojunga (1932); Ziraldo (1932); Mauricio de Souza (1935); etc.

Muitos desses escritores incorporaram em suas produções todas as demandas do quarto ciclo (1971-1984) da Literatura Infantojuvenil no Brasil. Nesse ciclo vemos que começou a florescer uma vasta produção dirigida aos jovens, geralmente com um cenário urbano e com narrativas que tematizam a pobreza, a miséria, a injustiça e a marginalidade. Dessa nova safra, destacam-se autores como Lygia Bojunga (1932), Ruth Rocha (1931), Ziraldo (1932), João Carlos Marinho (1935), Marina Colasanti (1937), Ana Maria Machado (1941), Pedro Bandeira (1942), Bartolomeu Campos de Queirós (1944), Angela Lago (1945-2017), Sérgio Caparrelli (1947), Eva Furnari (1948), Adriana Falcão (1960), Fernando Bonassi (1962), Flávio carneiro (1962), etc. Desse modo, cabe destacar que

[...] a literatura infantojuvenil brasileira contemporânea tem sido capaz de resgatar a história, de caminhar pela metaficção historiográfica, trazendo os discursos dos excluídos e esquecidos. Tem sido capaz de caminhar pela diversidade étnica e cultural brasileira, dando espaço para a criança imaginar e construir sua subjetividade, lidar com a afetividade, enfrentar a dor e os conflitos e descobrir a esperança e a alegria. [...] Um número significativo de autores experientes e premiados, com reconhecimento de público e de crítica, garantem, ao lado de novos autores, uma produção constante e de reconhecida qualidade estética. Não se pode negar, contudo, uma imposição de mercado presente no panorama editorial brasileiro, exigindo da crítica um esforço em distinguir as obras com qualidades literárias daquelas que atendem, apenas, a um forte apelo mercadológico. (TURCHI, 2006, p. 26).

A escola, aferrada ainda à tradição e à colonização, dificilmente abre suas portas e mentes às leituras mais contemporâneas endereçadas ao público infantojuvenil, pois segue nela a ideologia moralizante e de "proteção" idealizada que busca "impedir" que a criança entre em contato com a realidade que, de fato, vivemos. Assim, começa na escola o processo de alienação. Desse modo, a criança pode viver, na pele, em sua casa, na rua e em quase todos os espaços sociais, os processos de divórcio, de morte, de discriminação, de abuso e violência... mas, hipocritamente, na escola ela não pode "ler" 
sobre isso, pois precisa ser "preservada", aprendendo os "bons costumes" que ela mesma vê, tantas vezes, sendo abertamente quebrados nas práticas interativas.

Ao escolher um corpus de leitura literária, ou mesmo outro qualquer, olhares enviesados são lançados às obras mais recentes, justamente por tratarem de temáticas que problematizam para o jovem leitor situações reais da contemporaneidade. Escritores como Daniel Munduruku (1964), Olívio Jekupé (1965), Maurício Negro (1968), Ilan Brenman (1973), Fernando Vilela (1973), Ana Terra (1985), Kéfera Buchmann (1993), entre outros mais jovens, raramente aparecem como opções. Duas são as possíveis razões para isso:

- O controle que se exerce na escola, por diferentes agentes, sobre o que se pode ou não ler nesse espaço social ou, então,

- O total desconhecimento sobre a existência desses autores e suas obras por parte dos professores, conservadores, que tão confortável se sentem com "a cigarra e a formiga", "o Patinho feio", "Cinderela", ou "os três porquinhos".

A verdadeira democratização do acesso à aprendizagem da leitura e da escrita ainda hoje não é geral nos países latino-americanos. No Brasil, faz apenas 130 anos que as mulheres, afrodescendentes e indígenas têm direito a frequentar uma escola. Nesse sistema estratificado, disfrutaram do poder da palavra escrita somente uma pequena porcentagem da elite dominante. Essa situação segue sendo, pois, reproduzida dentro da escola como instituição responsável pelo ensino, prática e exercício da leitura e da escrita: atividade relegada aos professores das áreas humanas e, dentro dessa, mais especificamente ao professor do ensino fundamental e, mais adiante, responsabilidade, quase exclusiva, do professor de língua portuguesa.

Somente a leitura, entendida como uma atividade social e reflexiva - cujos objetos não devem ficar atrelados apenas à tradição - pode propiciar uma relação criativa, crítica e libertadora com a escrita - capacidade na qual se revela, em potencial, o poder da palavra na construção ideológica, discursiva e argumentativa. Esse conhecimento ensinado e aprendido - mostra-se como um desafio para qualquer processo de democratização e transformação social coletivo.

Ao fazer-se da leitura uma prática essencial do Ensino Fundamental e Médio ancorada no próprio processo evolutivos das escritas endereçadas aos estudantes estaremos formando cidadãos mais plenos e conscientes de sua atuação como agentes históricos. Ao reivindicarmos do poder vigente as condições para tal ensino na escola, exercitamos nossa cidadania, pois nessa prática se incluem diretos e deveres essenciais do cidadão e do governo.

À escola cabe, por excelência, o papel de formar leitores capacitados para estabelecer a leitura crítica do mundo. A sociedade pode e deve participar dessa tarefa. Contudo, é no espaço institucional da escola onde o processo de leitura precisa ser instaurado e conduzido para transformar-se em um ato crítico de reflexão. Conforme defende Silva (2005, p. 16), "o papel da escola é o de formar leitores críticos e autônomos capazes de desenvolver uma leitura crítica do mundo. Contudo, esta noção parece perder-se diante de outras concepções que ainda orientam as práticas escolares." 
Quando avançamos na formação escolar dos pequenos leitores, chega a hora deles se enfrentarem com mais afinco, já nos anos finais do Ensino Fundamental II, à leitura do "gênero proibido": o romance. Nossos aprendizes de leitura literária precisam ser "informados" sobre a trajetória deste gênero dentro da nossa condição de colônias, para que possam adentrar este mundo de construção artística, na passagem para o Ensino Médio, de forma consciente. O romancista e crítico literário peruano - ganhador do prêmio Nobel de Literatura - comenta em seu ensaio "A verdade das mentiras":

Los inquisidores españoles, por ejemplo, prohibieron que se publicaran o importaran novelas en las colonias hispanoamericanas con el argumento de que esos libros disparatados y absurdos - es decir, mentirosos - podían ser perjudiciales para la salud espiritual de los indios. [...]. Al prohibir no unas obras determinadas sino un género literario en abstracto, el santo Oficio estableció algo que a sus ojos era una ley sin excepciones: que las novelas siempre mienten, que todas ellas ofrecen una visión falaz de la vida. [...] Ahora pienso que los inquisidores españoles fueron acaso los primeros en entender - antes que los críticos y que los propios novelistas - la naturaleza de la ficción y sus propensiones sediciosas. ${ }^{1}$ (VARGAS LLOSA, 2002, p. 15-16).

Segundo Antunes, "não se nasce com o gosto pela leitura, [...]. O ato de ler não é, pois, uma habilidade inata. [...] o gosto por ler literatura é aprendido por um estado de sedução, de fascínio, de encantamento. Um estado que precisa ser estimulado, exercitado e vivido." (ANTUNES, 2009, p. 201). Nas palavras de Gonçalves (2009, p. 17), vemos que "a leitura literária constitui, através do prazer e da descoberta que pode proporcionar, um caminho de aprendizagem da língua que contribui para a formação integral do ser humano. O Ensino da Literatura legitima-se na convicção de que a leitura de textos literários constitui um componente relevante na formação cultural do leitor e no seu reconhecimento do mundo, dos outros e de si mesmo."

A leitura fruição é uma prática que precisa ser resgatada na escola. Esta é a leitura que, segundo Geraldi (2006), "está ligada ao prazer, ler por ler, sem interesse pelo controle de resultado, ler gratuitamente". Algo que vemos possível e significativo quando é realizado com um trabalho voltado ao texto literário, pela leitura subjetiva que tais textos promovem. O encanto pela leitura deve começar na infância, incentivado pela família, estimulado e, estrategicamente, induzido na escola.

\footnotetext{
${ }^{1}$ Nossa tradução: Os inquisidores espanhóis, por exemplo, proibiram que se publicassem ou importassem romances nas colônias hispano-americanas com oi argumento de que esses livros disparatados e absurdos - é dizer, mentirosos - podiam ser prejudiciais para a saúde espiritual dos índios. [...]. Ao proibir não umas obras determinadas, porém um gênero literário em abstrato, o santo Ofício estabeleceu algo que a seus olhos era uma lei sem exceções: que os romances sempre mentem, que todos eles oferecem uma visão falaz da vida. [...] Agora penso que os inquisidores espanhóis foram, por acaso, os primeiros em entender - antes que os críticos e que os próprios romancistas - a natureza da ficção e suas propensões sediciosas.
} 


\section{PORQUE O ENSINO DE LITERATURA É PERIGOSO AO SISTEMA COLONIAL AINDA PERSISTENTE NA AMÉRICA?}

O sistema colonial sempre se aproveitou, eficazmente, de discursos instituídos nas sociedades estratificadas, aplicando-os como máximas a serem observadas para que o sujeito se "acomodasse" e se "conformasse" com sua situação. Desse modo, tornar conhecido e praticado pensamentos como "felizes são os pobres porque herdarão o reino dos céus", entre muitos outros, chega a ser providencial já que em nossa história colonial a grande maioria dos negros, indígenas e mestiços eram os pobres a se resignar a esta sorte já que pelo sistema instituído eles não herdavam nada, e, no caso dos mestiços, em especial, nem o sobrenome dos pais. Possibilitar a circulação e a produção de obras ficcionais nas quais outras possíveis realidades sejam expostas para que tais leitores possam "cogitar" diferentes perspectivas para a sua própria existência torna-se um ato altamente perigoso. Tal ato de "rebeldia" poderia despertar desejos humanos retraídos e sufocados pela elite dominadora, pois

[...] la literatura abre todas las puertas, todos los deseos y todos los estilos de ver y obrar: la literatura contiene todas las expresiones del ser humano y tiene más permanencia que reyes y presidentes, a quienes tarde o temprano sepulta la historia, dejando en algunos apenas una remembranza, como no ha ocurrido por ejemplo a Don Quijote de La Mancha. La literatura, la buena, es perene y mantiene su influencia en todas las épocas. ${ }^{2}$ (OSORIO, 2010, p. 14).

Essa característica "transgressora" do texto literário é também comentada por Vargas Llosa (2002) quando afirma que "la literatura nos permite vivir en un mundo cuyas leyes transgreden las leyes inflexibles por las que transcurre nuestra vida real, emancipados de la cárcel del espacio y del tiempo, en la impunidad para el exceso y dueños de una soberanía que no conoce límites. " " (VARGAS LLOSA, (2002, p. 394). O crítico comenta em seu texto que, ao dar-se conta dessas possibilidades da ficção, os Inquisidores espanhóis foram os que, antes mesmo dos críticos e dos próprios romancistas, dimensionaram o poder "libertador" do discurso ficcional que, segundo ele, são, sim, textos mentirosos, pois, "en efecto las novelas mienten - no pueden hacer otra cosa - pero ésa es sólo una parte de la historia. La otra es que, mintiendo, expresan una curiosa verdad, que sólo puede expresarse encubierta, disfrazada de lo que no es. ${ }^{4}$ (VARGAS LLOSA, 2002, p. 16). Essa polissemia do romance levou os inquisidores

\footnotetext{
${ }^{2}$ Nossa tradução: [...] a literatura abre todas as portas, todos os desejos e todos os estilos de ver e obrar: a literatura contém todas as expressões do ser humano e tem mais permanência que reis e presidentes, a quem mais cedo ou mais a história sepultará, deixando em alguns apenas uma vaga lembrança, como não ocorreu, por exemplo, com o Don Quijote de La Mancha. A literatura, a boa, é perene e mantém sua influência em todas as épocas.

${ }^{3}$ Nossa tradução: A literatura nos permite viver em um mundo cujas leis transgredem as leis inflexíveis pelas quais transcorre nossa vida real, emancipados do cárcere do espaço e do tempo, na impunidade para o excesso e donos de uma soberania que não conhece limites.

${ }^{4}$ Nossa Tradução: Em efeito os romances mentem - não pode fazer outra coisa - mas essa é só uma parte da história. A outra é que, mentindo, expressam uma curiosa verdade, que só pode ser expressa encoberta, disfarçada do que não é.
} 
a proibir sua circulação e sua produção no nosso continente que, assim, levou mais de 300 anos após a conquista até libertar-se dessa "prisão" e escrever o primeiro romance em nossas terras latino-americanas ${ }^{5}$.

Esteves (2010, p. 20), sugere que, mesmo que a literatura seja repleta de "mentiras", ela conta "[...] histórias que a história escrita pelos historiadores não sabe, não quer ou não pode contar. Os exageros da literatura servem para expressar verdades profundas e inquietantes que só dessa forma poderiam vir à luz." Nesse sentido, o "poder" formador do romance, desde a origem do colonialismo em nossas terras, tem sido fator de preocupação para o poder instituído e paras as instituições que veiculam as ideologias que tal exercício requer. A elite colonizadora sempre esteve, desde os Inquisidores, conscientes de que

[...] a literatura pode formar; mas não segundo a pedagogia oficial. [...]. Longe de ser um apêndice da instrução moral e cívica, [...], ela age com o impacto indiscriminado da própria vida e educa como ela. [...]. Dado que a literatura ensina na medida em que atua com toda a sua gama, é artificial querer que ela funcione como os manuais de virtude e boa conduta. E a sociedade não pode senão escolher o que em cada momento lhe parece adaptado aos seus fins, pois mesmo as obras consideradas indispensáveis para a formação do moço trazem, freqüentemente, aquilo que as convenções desejariam banir. [...]. É um dos meios pelos quais o jovem entra em contato com realidades que se tenciona escamotear-lhe. (CANDIDO, 1972, p. 805).

O poder da literatura, ora sutil, ora declarado, é capaz de atuar na formação do indivíduo que lê, pois este, por meio da arte literária, terá suas ideias e vivências colocadas em contraste com outras, talvez mais aguçadas, ou mais sensíveis, provenientes de diferentes realidades. Esse embate resultará em reflexões, e essas, em novas posturas, quiçá moldadas por valores mais dialógicos, diferentes daqueles da pedagogia oficial, cerceadores e dominantes. Assim, "la ficción enriquece su existencia, la completa, y, transitoriamente, los compensa de esa trágica condición que es la nuestra: la de desear y soñar siempre más de lo que podemos alcanzar." (VARGAS LLOSA, 2002, p. 29). Possivelmente disso resulte também a humanização do leitor que Candido (2004, p. 176) aponta: "a literatura não corrompe nem edifica, mas humaniza em sentido profundo, por que faz viver." Conforme explicita Candido (2004, p. 180):

Humanização é o processo que confirma no homem aqueles traços que reputamos essenciais, como o exercício da reflexão, o afinamento das emoções, a capacidade de

\footnotetext{
${ }^{5}$ Trata-se da obra Periquillo Sarniento, do mexicano José Joaquim Fernández de Lizardi, publicado no ano de 1816. Essa obra é apontada por vários estudiosos como a obra introdutória do gênero romanesco na América Latina. No contexto brasileiro, cronologicamente estabelecido, o primeiro romance produzido foi $O$ Filho do Pescador, publicado em 1842, de autoria de Teixeira e Souza (1812-1881). Essa narrativa constitui-se em um romance sentimentalista que não havia "absorvido" as dimensões da escrita romântica europeia da época, que se impunham também na produção do nosso continente. Dois anos após essa publicação, Joaquim José de Macedo lança $A$ Moreninha, obra romântica que passa a ser vista como o "verdadeiro" primeiro romance da Literatura Brasileira.

${ }^{6}$ Nossa tradução: A ficção enriquece sua existência, completa-a, e, transitoriamente, compensa-nos dessa trágica condição que é a nossa: A de desejar e sonhar sempre com mais do que podemos alcançar.
} 
penetrar nos problemas da vida, o senso de beleza, a percepção da complexidade do mundo e dos seres, o cultivo do humor.

Será que a forma como procedemos ao ensino da leitura na escola tem levado nosso aluno a isso? É preciso construir caminhos de interesse e familiarização com os textos, dos mais simples aos mais complexos, num processo de amadurecimento, oferecendo aos educandos o texto literário a princípio para uma familiarização e identificação, com obras mais simples para, aos poucos, acrescentar as mais elaboradas e que demandam operações linguísticas e relações intertextuais mais complexas; uma prática que requer a mediação: uma sistemática, um planejamento, uma continuidade que conduza à satisfação e à realização pessoal, em primeira instância e, mais adiante, ao árduo trabalho da leitura crítica, do enfrentamento entre o lido e a realidade circundante em um grau mais consciente e profundo. Mediação é isso.

Nesse sentido, uma lacuna a ser preenchida no âmbito escolar, quanto ao trabalho com a Literatura e o vital processo de mediação do professor para que tal texto encontre acolhida pelo estudante, é compreender e explicitar o pacto de leitura, expressão utilizada por Geraldi (1997), que o leitor estabelece com o material a ser lido. O leitor, quando interage com o texto, percorre um caminho em uma relação de interesses entre ele mesmo e o autor, aquele que constrói o texto. Assim, o leitor interpreta e reconstrói, a partir de leituras prévias e também da leitura do mundo em que vive, o texto produzido pelo autor, dando-lhe, nesse processo, um significado particularizado que o torna valioso como mensagem.

Para Freire (2003, p. 18), o ato de ler está envolvido em um processo "que não se esgota na decodificação pura da palavra escrita ou da linguagem escrita, mas que se antecipa e se alonga na inteligência do mundo." A formação de um leitor pleno, proficiente, tem como resultado um cidadão pensante, capaz de assimilar aquilo que lê, que tem a leitura como uma ferramenta capaz de facilitar sua vida e ajudá-lo a compreender e experienciar o mundo. Já a escrita passa a ser, para este leitor, um meio de expressão privilegiado que pode lhe garantir seus direitos.

Para Silva (2002, p. 75), "ler é um direito de todos e, ao mesmo tempo, um instrumento de combate à alienação e à ignorância”, pois um bom leitor ganha liberdade de escolha, uma vez que tem controle do que lê e condições de criticar aquilo que lê, não se deixando levar pela superficialidade nem pela interpretação de terceiros. Gêneros variados de leitura cooperam, sem dúvidas, para uma melhor integração do sujeito com o mundo letrado, mas nenhum texto é mais indicado para formar leitores críticos e conscientes do que o texto literário. Isso por que é de natureza "aberta" e nele o leitor será, sempre, coautor. Mas, aqui, a mediação é vital.

Aprender é um modo de inserir-se no mundo social, juntamente com outras pessoas e, desse modo, estar envolvido em um contexto histórico, cultural e institucional, porque essa é uma tarefa que compete a professores e estudantes realizar conjuntamente. Ao concebermos a aprendizagem dessa forma estaremos oferecendo muito mais oportunidades para que os aprendizes se expressem ao longo do processo. Assim, a trajetória de aprendizagem deve ser desenvolvida levando-se em conta as necessidades sociais do aprendiz. Os estudantes costumam vir de realidades sociais 
distintas, convivendo em situações diferenciadas e, de acordo com Wigotsky (1985), seu processo de aprendizagem dependerá de cada um dos aspectos que os envolve (como são educados em casa, seu conhecimento prévio, e tudo aquilo que os circunda em seu dia a dia).

O ato de ler é social, é uma prática que permite ao aluno uma vivência entre o que se lê e o mundo em que se vive. Para Bakhtin (1992), a leitura é capaz de transformar o indivíduo em um sujeito ativo, responsável pela sua aprendizagem, que sabe compreender o contexto em que vive e modificá-lo de acordo com a sua necessidade. A história da formação docente no Brasil não nos dá muitas mostras de que se tenha buscado ao longo dos séculos "transformar o indivíduo em um sujeito atuante, responsável por sua aprendizagem”. Ao contrário, somos, muitas vezes, simplesmente resignados, conformados frente às injustiças, à pobreza, à miséria, à falta de condições existenciais mínimas, quando vivemos em um dos países mais ricos em recursos naturais.

Desse modo, é a concepção de leitura, na perspectiva dialógica social, que fundamenta ações de formação leitora voltadas à geração de alunos "responsáveis por sua aprendizagem", que compreendam a realidade que os cerca e lhes aponta possibilidades de ações efetivas na transformação daqueles aspectos que não lhe possibilitam viver bem. Trabalhar sob esta perspectiva teórica inclui jamais conceber o processo de entrada no mundo letrado, pela alfabetização normalmente, como um conjunto de regras mecânicas e técnicas que oferecem ao sujeito as condições de relacionar, de forma mais ou menos eficaz, o signo com seu significante. Compartimos a concepção de Paes de Barros (2005), quando menciona que a leitura é

[...] uma prática social em que atuam autor e leitor em uma situação de enunciação. Nessa concepção, a leitura é vista como um processo de compreensão ativa no qual os diversos sentidos em circulação no texto são instituídos a partir da relação dialógica estabelecida entre autor e leitor, entre leitor e texto e entre a multiplicidade de linguagens sociais que permeiam essas instâncias. [...] a leitura, nessa concepção, é um processo dialógico que promove um encontro entre discursos e enunciados, que acabam por construir conjuntamente os sentidos dos textos. (PAES DE BARROS, 2005, p. 32).

Essa prática de leitura só é possível com um leitor não alienado, adequadamente mediado pelo professor. O processo de construção de sentidos, conectado ao ato de decodificação dos signos linguísticos, só é possível, no começo da formação escolar, quando a criança se sente estimulada à imaginação, à fabulação, à fantasia - questões subjetivas que ancoram o processo bem sucedido de aprendizagem de leitura. O estímulo desses apectos possibilita ultrapassar os limites da concretude visual, tátil, olfativa, gustativa e auditiva que, até o momento da alfabetização, foram as bases de leitura de mundo que a criança vinha efetuando. O passo necessário entre esta leitura da concretude com a qual a criança vem para a escola para a seguinte: a leitura simbólica das palavras, não é um passe de mágica.

Somente a leitura, entendida como uma atividade social e reflexiva, pode propiciar uma relação criativa, lúdica, crítica e libertadora com a escrita, mostrando-se como um desafio para qualquer processo de democratização e transformação social coletivo. Ao 
fazer-se dela a prática essencial do Ensino Fundamental e Médio estaremos formando cidadãos mais plenos e conscientes de sua atuação como agentes históricos.

A vital mediação do professor nesse processo consite, entgre outras ações, em oportunizar às crianças as mais variadas e significativas experiências com os meios corriqueiros e cotidianos de "representação" e "simbolização" que elas já conhecem mas que, no universo da concretude, nunca necessitaram de "reflexão" para a sua compreensão. Tais processos - muitas vezes complexos, assim como é aquele da escrita para a qual a criança deve ser preparada - são por ela, e pela própria sociedade, tidos como "normais", "regulares", "comuns". A mediação necessária é para que a criança entenda que, ao aprender a escrever, ela estará ampliando a sua capacidade de "representar", de "simbolizar", ações que ela já sabe fazer com outros sistemas que não são as "letras".

A função social da escola durante o Ensino Fundamental é a de formar estudantes que tenham o gosto, o hábito e o prazer da leitura instaurados em sua subjetividade. A criticidade da qual tanto se fala é função das fases posteriores da trajetória educacional, pois nenhuma criticidade no ato de leitura se pode desenvolver - nem na escola, nem na vida - se essa prática for considerada uma atividade difícil, enfadonha, limitadora. Resultado deste sistema imperante na educação brasileira é o inegável fato de que a habilidade consequente da leitura crítica: uma escrita também proficiente é o "ponto fraco" da grande maioria dos professores, inclusive aqueles que ensinam Língua Portuguesa.

\section{CONSIDERAÇÕES FINAIS}

O ensino da literatura deve, se queremos de fato uma sociedade leitora, voltar a ocupar o seu merecido espaço na escola, tanto nas ações dos professores enquanto docentes e leitores capacitados bem como no espaço curricular. Zilbermann (2004) chama atenção para a leitura literária como modalidade de educação e esclarece que, na trajetória do ensino da literatura, por muitos séculos, o conhecimento dos clássicos e do cânone consagrado foram privilegiados, mas, nas últimas décadas, "[...] primeiro jogouse ao mar a carga da história; depois, foi abandonada a própria literatura, desfeita na definição imprecisa de texto". (2004, p. 18). E acrescenta que “[...] essas opções decorreram de um processo, ele mesmo, histórico, relacionado à ascensão à escola pelas classes populares, que, assim, permanecem alienadas da tradição e do passado, ao qual podem não pertencer, com o qual podem não se identificar, mas que se relaciona à formação da identidade nacional, com a qual devem interagir, seja para aceitá-la, seja para contrariá-la." (ZILBERMANN, 2004, p. 18).

Sem que a sociedade se desse, de fato, conta, projetos mais amplos foram excluindo do espaço escolar o lugar privilegiado que a literatura tinha quando o acesso ao sistema era muito mais elitizado. $\mathrm{Na}$ atualidade o que vivemos é a "marginalização" da literatura - um bem cultural que deveria, conforme defende Candido (2004), ser de acesso a todos. Enquanto as classes populares foram, gradativamente, acedendo à escola, as reformas educacionais foram impedindo que essas classes tivessem, 
verdadeiramente, contato, na instituição, com a riqueza e a profundidade dos ensinamentos da literatura.

Descolonizar a grande massa populacional do nosso país passa, necessariamente, pelo aprendizado da leitura, esse feito como uma caminhada formativa que explora desde os primeiros níveis de interação do sujeito com o mundo - o nível sensorial - até aquele que lhe permite humanizar-se, pela linguagem e o trabalho - por meio do acesso à leitura emotiva ou subjetiva - até ao ato comprometido da leitura racional que, em suas diferentes etapas (compreensiva, interpretativa e conscientizador), pode levar à criticidade.

A escola deve ser o espaço institucional responsável por essa descolonização ainda necessária e o processor, continuamente levado a refletir, pela formação continuada, precisa assumir-se como leitor e, a partir da sua experiência própria, conquistar os alunos para desenvolver o hábito, o gosto e, daí, o prazer no ato de ler.

\section{REFERÊNCIAS}

ANTUNES, I. Lingua, Texto e Ensino: outra escola possível. São Paulo: Parábola, 2009.

CAGLIARI, L. C. Alfabetização e linguística. São Paulo: Scipione, 2005. (Coleção Pensamento e Ação no Magistério).

CAGLIARI, L. C. Alfabetização \& Lingüística. São Paulo: Scipione, 1992.

CAGLIARI, L. C. Alfabetizando sem o ba-be-bi-bo-bu. São Paulo: Scipione, 1998.

CANDIDO, A. A literatura e a formação do homem. São Paulo: Ciência e Cultura, v. 24, n. 9, p. 803-809, 1972.

CANDIDO, A. O direito à literatura. In: Vários escritos. (4.ed. reorg. pelo autor). São Paulo: Duas Cidades, 2004.

CANDIDO, A. Direitos humanos e literatura. In.: FESTER, A. C. Ribeiro e outros. São Paulo: Brasiliense, 1989.

CANDIDO, A. O direito à literatura. In: Vários escritos. Rio de Janeiro: Ouro sobre Azul, 2011.

COLOMER, T. Andar entre livros: a leitura literária na escola. São Paulo: Global, 2007.

BAKHTIN, M. Marxismo e filosofia da linguagem. 6.ed. São Paulo: Hucitec, 1992.

BORDINI, M.G.; AGUIAR, V. T. de. A formação do leitor: alternativas metodológicas. Porto Alegre: Mercado Alegre, 1988.

ESTEVES, A. R. O romance bistórico brasileiro contemporâneo (1975-2000). São Paulo: Ed. UNESP, 2010.

FLECK, G. F. Formação do Leitor: um projeto socioeducacional - uma trajetória para a vida cidadã. In: FLECK, G. F. (Org.). Literatura Infantojuvenil: desafios para o letramento literário - pesquisas e experiências no âmbito escolar. Curitiba: CRV, 2017.

FREIRE, P. Pedagogia do Oprimido. 36.ed. Rio de Janeiro: Edições Paz e Terra, 2003.

GERALDI, J, W. Portos de Passagem. 4.ed., São Paulo: Martins Fontes, 1997.

GERALDI, J, W. O texto na sala de aula (Org.). São Paulo: Ática, 2006.

GONÇALVES, R. CAZZARAI, M.P. (orgs.) Ler acima de todas as coisas. In: Lingua e literaturas: perspectivas de ensino. Guarapuava: UNICENTRO, 2009. 
MARTINS, M. H. O que é Leitura. 19º ed., São Paulo: Brasiliense, 2012.

MONTES, G. La frontera indómita: en torno de la construcción y defensa del espacio poético. Buenos Aires: F.C.E., 2001.

OSÓRIO, L. B. Y. La promoción de la lectura en tiempos aciagos y el pequeño cuchillo de La bibliotecária Chun Li. In Aportes para la promoción de la literatura y la lectura. Maén Puerta (compilación). Facultad de Humanidades y Educación y El Consejo de Publicaciones de La Universidad de Los Andes. Venezuela: Mérida, 2010.

PAES DE BARROS, C. G. Compreensão ativa e criadora: uma proposta de ensinoaprendizagem de leitura do jornal impresso. Tese de doutorado apresentada ao LAEL da PUC São Paulo, 2005. Disponível em www.pucsp.br/pos/lael/lael-inf/ def_teses.html.

RAMALHO, B. L.; NUÑEZ, I. B.; GAUTHIER, C. Formar o professor, profissionalizar o ensino: perspectivas e desafios. 2.ed. Porto Alegre: Sulinas, 2004.

SAVIANI, D. Formação de professores: aspectos históricos e teóricos do problema no contexto brasileiro. In: Revista Brasileira de Educação, v. 14, n. 40, p. 143-155, 2009.

SILVEIRA, M. I. M. . Modelos Teóricos e Estratégias de Leitura: suas implicações no ensino. Maceió: EDUFAL, 2005.

SILVA, I. M. M. Literatura em sala de aula: da teoria literária à prática escolar. Recife: Programa de Pós-Graduação em Letras da UFPE, 2005.

SOARES, M. Letramento. Belo Horizonte: Autêntica, 1998.

TURCHI, M. Z.; SILVA, V. M. T (Org.). Leitor formado, leitor em formação - leitura literária em questão. São Paulo: Cultura Acadêmica; Assis: ANEP, 2006.

VARGAS LLOSA, M. La verdad de las mentiras. Buenos Aires, Aguilar, Altea, Taurus, Alfaguara, S/A, 2002.

VIGOTSKI, L. S. Psicologia e Pedagogia II: investigações experimentais sobre problemas didáticos específicos. v. 2. Lisboa: Biblioteca de Ciências Pedagógicas - Ed. Estampa, 1977.

ZILBERMANN, R. Estética da recep̧̧ão e história da literatura. São Paulo: Ática, 2004. 